\title{
Effects of surface sorption on microbial degradation of glyphosate
}

\author{
Supporting Information
}

\author{
Ylva Schnürer ${ }^{1}$, Per Persson $^{2}$, Mats Nilsson ${ }^{1}$, Anders Nordgren $^{1}$, Reiner Giesler ${ }^{* 3}$ \\ ${ }^{1}$ Department of Forest Ecology, Swedish University of Agricultural Sciences, 90187 \\ Umeå, Sweden \\ ${ }^{2}$ Department of Chemistry, Aquatic Chemistry, Umeå University, 90187 Umeå, Sweden \\ ${ }^{3}$ Climate Impact Research Centre, Department of Ecology and Environmental Science, \\ Umeå University, Box 62, 98107 Abisko, Sweden \\ *Corresponding author \\ Phone: +46 98040013 69; fax: +4690786 6705 e-mail: reiner.giesler@emg.umu.se
}

Pages: 4

Figures: 3 

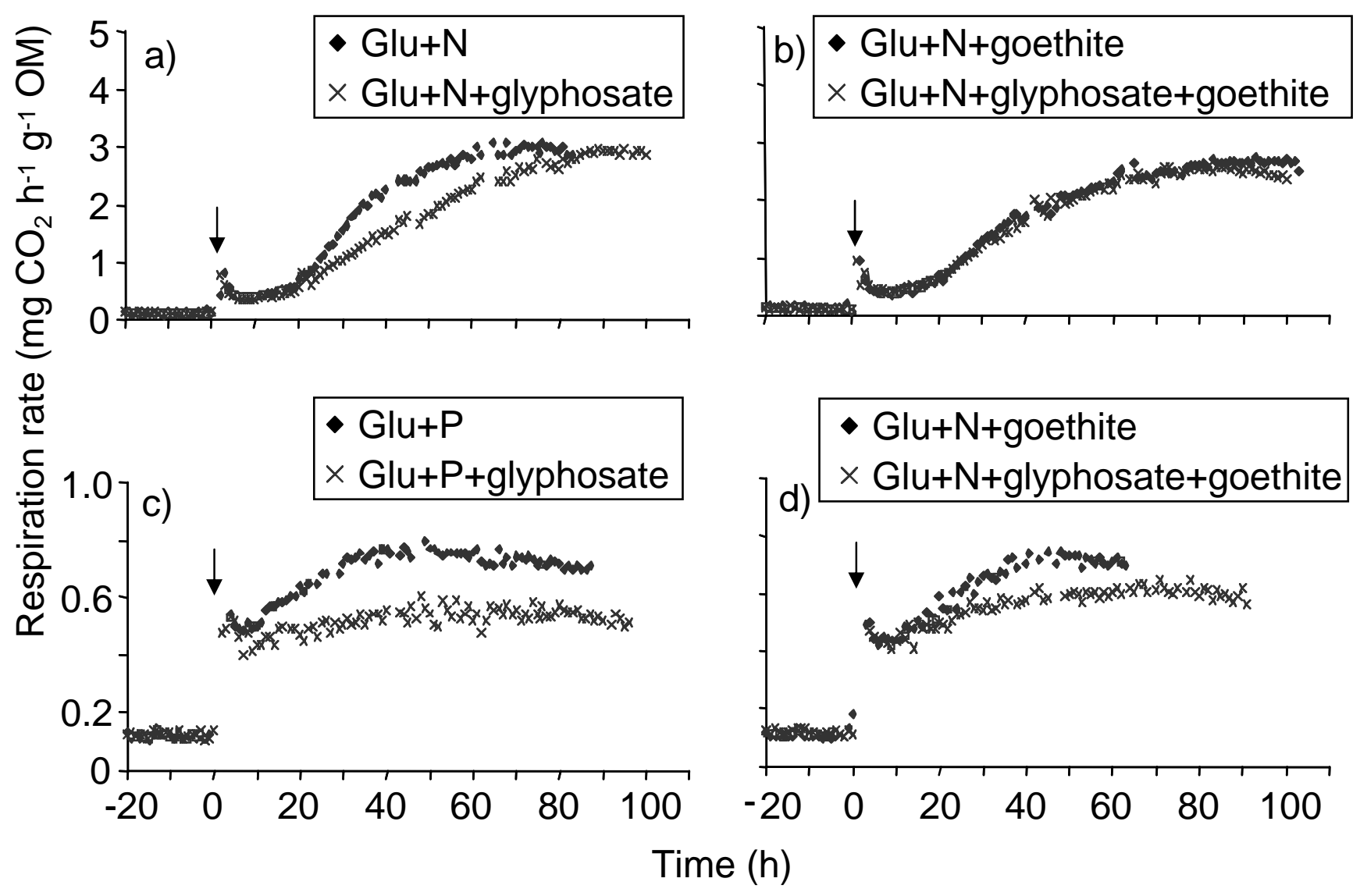

Figure S1. Microbial respiration responses in experiment 1 after additions of glyphosate in combination with a) glucose (Glu) and $\mathrm{N}$ without goethite; b) glucose and $\mathrm{N}$ with goethite; c) glucose and $\mathrm{P}$ without goethite; and d) glucose Diamonds denote controls without glyphosate and the arrow denotes the time of addition. 
$\Delta+$ goethite $+\mathrm{CaCO}_{3}$

$\square$ - goethite $+\mathrm{CaCO}_{3}$

$\Delta$ + goethite

- - goethite

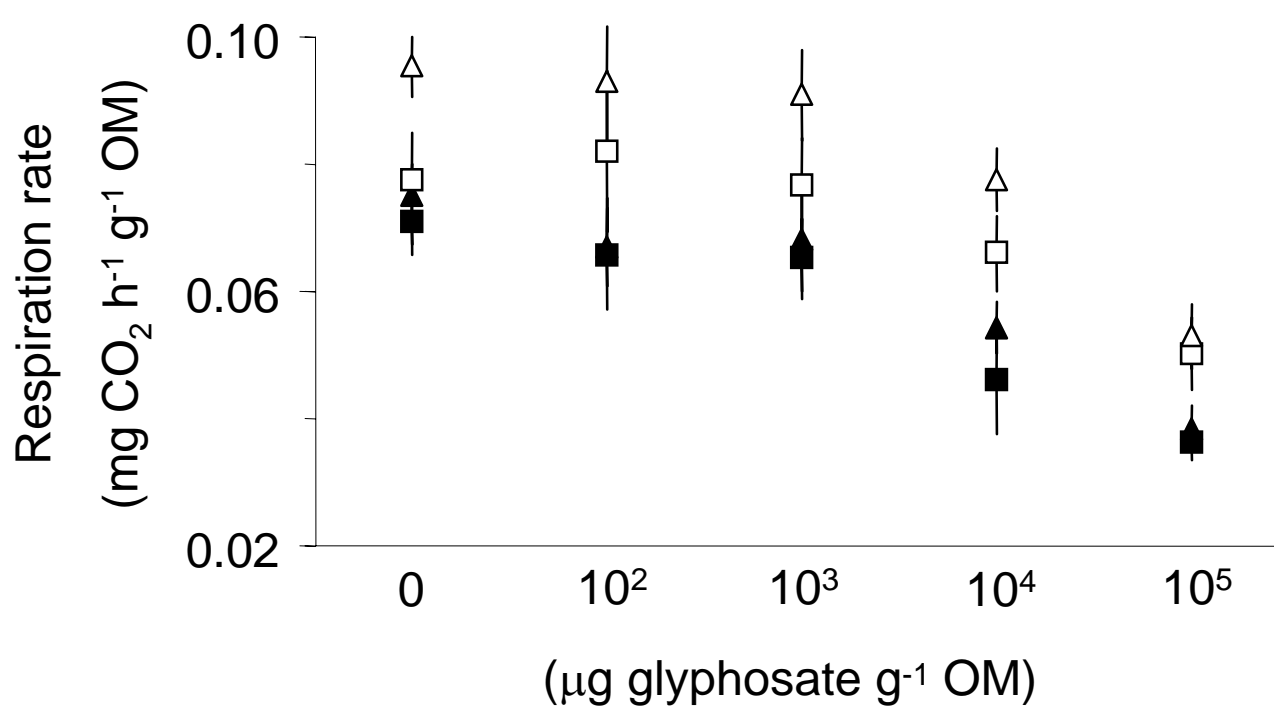

Figure S2. Microbial respiration responses in experiment 2 after additions of glyphosate, without and without goethite. The unfilled symbols represent respiration rates after additions of $\mathrm{CaCO}_{3}$ to increase the soil $\mathrm{pH}$. Additions of glyphosate and goethite where done at the start of the experiment. The values represent average and $95 \%$ confidence intervals. 


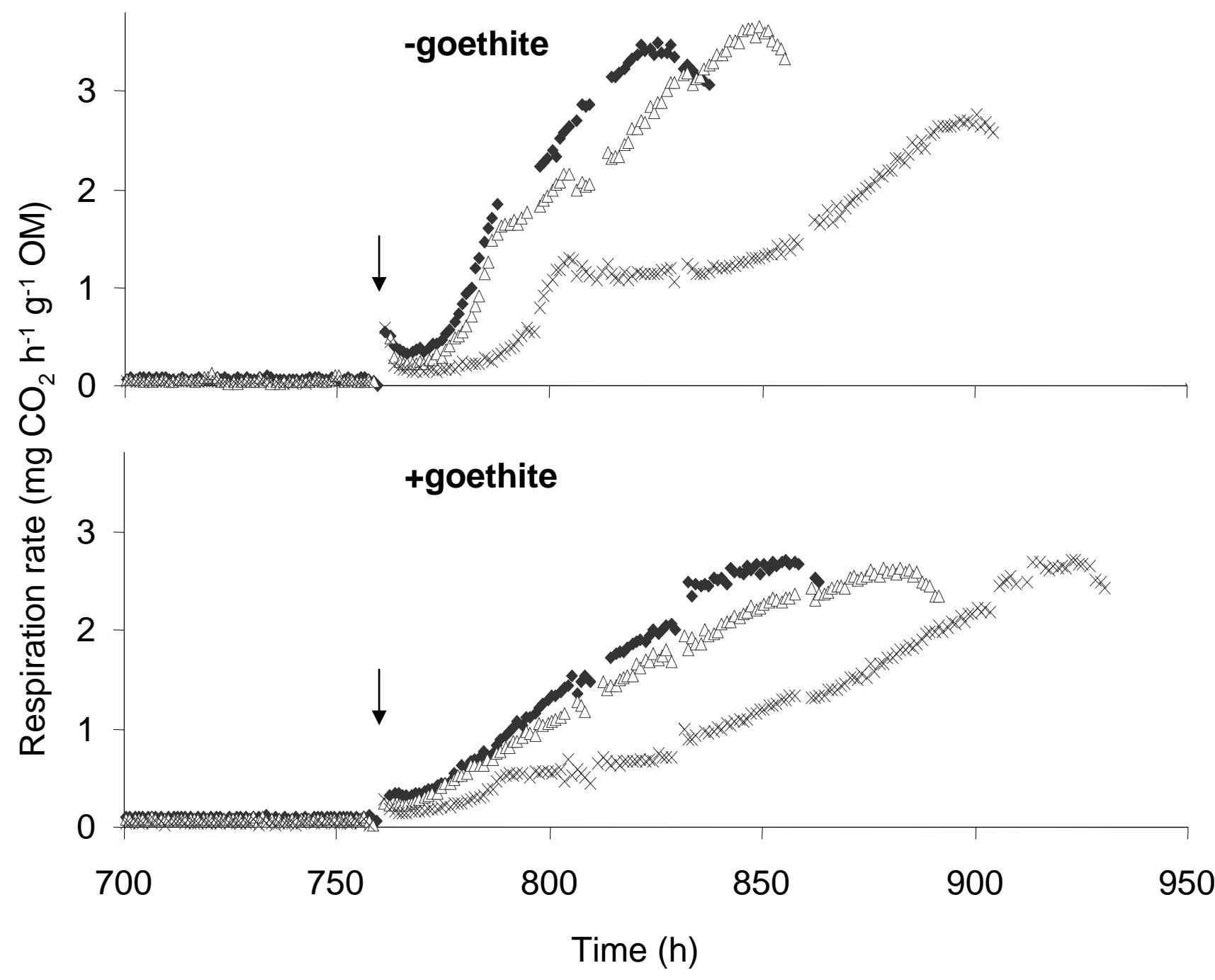

Figure S3. Microbial respiration responses in experiment 2 after additions of glucose and $\mathrm{N}$, without and with goethite, combined with additions of 0 (filled diamonds), $10^{4}$ (unfilled triangles), and $10^{5} \mu \mathrm{g}$ glyphosate $\mathrm{g}^{-1} \mathrm{OM}$ (crosses). Additions of glyphosate and goethite where done at the start of the experiment and glucose and $\mathrm{N}$ after $780 \mathrm{~h}$. Arrows denote additions of glucose and N. 